THE OXIDATIVE METABOLISM OF SPARTEINE IN THE CUNA

AMERINDIANS OF PANAMA: ABSENCE OF EVIDENCE FOR DEFICIENT METABOLIZERS

T. D. ARIAS, Ph.D.,

L. F. JORGE, M.Sc., D. LEE, M.D.,

R. BARRANTES, Ph.D., and

T. INABA, Ph.D.,

Panamá, Repủblica de Panamá, San José, Costa Rica, and Toronto, Canada

From the World Health Organiration Center for Dray Quality Control, Instituto Eepecializado de Andlisis, and the Collecse of

Pharmacy, Univeraity of Panamt, the Inetituto de Invea-

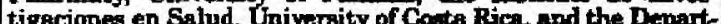
tigaciones en Salud, Uaversity of Coots nca, and the Department of Pharmacology, Faculty of Mectieine, Univarity of To ronto.

Reprinted from

CIINICAL PHARMACOLOGY AND THERAPEUTICS, St. Louis

Vol. 43, No. 4, pp. 456-465, April, 1988 (Copyright (c) 1988, by The C.V. Mosby Company) (Printed in the U.S.A.) 


\title{
The oxidative metabolism of sparteine in the Cuna Amerindians of Panama: Absence of evidence for deficient metabolizers
}

\begin{abstract}
Sparteine sulfate ( $50 \mathrm{mg}$ ) was administered to 170 Cuna Amerindians, 142 of whom were unrelated, and the drug and its dehydrometabolites were determined in the 0 - to 12 -hour urine samples. The $\log _{10}$ of the metabolic ratio was unimodally, but not normally, distributed and showed the following values: mean $-0.21 \pm 0.26$, median -0.24 , limits -0.73 and 0.76 , skewness 1.00 , and kurtosis 4.95 . On the basis of these results, it can be concluded that there are no deficient metabolizers in the Cunz sample population studied. However, the similarity of the skewness found between the Cuna sample population

studied and the extensive Canadian white group, as well as an inflection point at $6.3 \mathrm{U}$ in the former's probit plot, suggests the existence of at least two subgroups congregating within the same single mode in the frequency distribution curve. The use of the inflection point is discussed thoroughly, conchuding that although it does not allow exclusion of the existence of genotypically different subgroups, the limitarions of the data do not permit its use to determine the number of heterozygotes and thus the existence of polymorphism. The possibility of an isozyme variant, consistent with the general genetic structure of Amerindians, as suggested by the coexistence of two subgroups within the unimodal curve, is entertained. (Cln Pharmacol. Ther 1988;43:456-65.)
\end{abstract}

\section{T. D. Arias, Ph.D., L. F. Jorge, M.Sc., D. Lee, M.D., R. Barrantes, Ph.D., and T. Inaba, Ph.D. Panamá, Repriblica de Panamá, San José, Costa Rica, and Toronto, Canada}

The oxidative biotransformation of sparteine has been associated in whites with the metabolism of debrisoquin and some clinically useful dnigs such as certain $\beta$-blockers, some tricyclic antidepressants, and others. ${ }^{1-3}$ in addition to whites, ${ }^{4}$ the genetic polymorphism of the metabolism of sparteine has been studied 7 acks ${ }^{5}$ and Japanese ${ }^{6}$ (Inaba T, Kalow W, unpublisined results).

To our knowledge no previous studies of the oxjdative biotransformation of sparteine in Amerindians and populations mixed with them. about 30 and 100 million, respectively, ${ }^{7-9}$ have been carried out. This ap-

From the World Health Organization Center for Drug Quality Control. Instituo Especializado de Analisis. and the College of Pharmacy. University of Panamá. the Instituto de Investigasciones en Saiud. University of Costa Rica, and the Depanment of Phamacolngy. Faculty of Medicine. University of Toronio.

Supported by the Regional Program for Scientific and Technoloyical Devclopment. Organization of American States. and the Medical Research Council of Canada.

Received for putlication Dec. 23. 1986: accepted Sept. 21. 1987.

Reprint requests: Professor T. D. Arias. Apartado 10767. Estafeta Universitaria. Panamá. Kepública de Panami parent neglect has occurred in spite of the relevance of this pathway and the demographic importance of these populations in Latin America. We therefore wish to confirm and expand our preliminary work, which we have recently described. ${ }^{\text {to.11 }}$

For these studies we selected the Cuna Amerindian group of Panama because it is one of the most populous (about 55,000) of the genetically homogeneous Amerindian groups. ${ }^{12-16}$

\section{METHODS}

Two hundred three Cuna volunteers from Panama were selected for the study. The subjects were inhabitants of Panama City and the Amerindian villages of Río Azúcar (Comarca de San Blas) and Kuna-Nega (Province of Panama). They were advised in Spanish or the Cuna language of their rights, as set down in the Helsinki Declaration, and were specifically requested not to drink any alcoholic beverages during the study:

Informed consent forms were signed and physical examinations and interviews were performed. Only healthy subjects of Cuna ancestry, as revealed through anamnesis. anthropometric criteria. and medical ex- 
amination, who were not taking any drugs were accepted for the study. A preliminary selection was carried out to exclude those subjects who were related in the fourth degree of consanguinity or closer. However, in certain cases in which potential problems of compliance were expected, the test drug was administered to more than one relative.

Each volunteer took $50 \mathrm{mg}$ sparteine sulfate at 6 PM after emptying the bladder and before dinner. The urine was collected overnight for 12 hours and, when the collection was made in the villages, the aliquots were kept on ice untiI taken to Panama City, where they were stored at $-20^{\circ} \mathrm{C}$.

After analysis of the urine, 28 subjects were elimiated because of the consanguinity exclusion criterion d 20 because of noncompliance, suspected compliance problems based on undetectable or very low amounts of recovered drug in the urine, or, in certain cases, because of abnormally low creatinine elimination. Another 12 subjects were eliminated for other reasons not related to the results of the analyses. We thus report the results obtained from only 142 subjects ( 77 males and 65 females; ages 16 to 70 years old; mean 35 years).

The samples were assayed according to a slight modification of the method of Inaba et al. ${ }^{17}$ in which methylene chloride was substituted by toluene to decrease the risk of damage to the nitrogen-phosphorus detector, as warned by its manufacturer (Varian Associates, Inc., Palo Alto, Calif.).

Statistical analysis. Differences between groups of the population, as classified by the place of collection of the samples, were evaluated by the Mann-Whitney - (nonparametric) test. The distributions of the recovsy of the drug, its 2- and 5-dehydrometabolites, and. the metabolic ratio (molar sparteine/dehydrosparteines) were analyzed by the $\chi^{2}$ goodness-of-fit test.

Because in certain cases this test is not able to detect certain departures from normality ${ }^{18}$ and we also wished to quantify them for comparisons of groups and populations, skewness and kurtosis of the various populations discussed were determined by the commercially available statistics program for microcomputers, Abstat (release 4, Anderson-Belt Co., Canon City, Colo.).

A measure of the amount of skewness in the population is given by the quantity called "the third moment about the mean." If the sample comes from a normal distribution, the coefficient of skewness is approximately normally distributed with a mean of 0 . In populations with positive skewness the higher tail is extended, whereas in populations with negative skewness - an extension is seen for the lower tail. A measure of

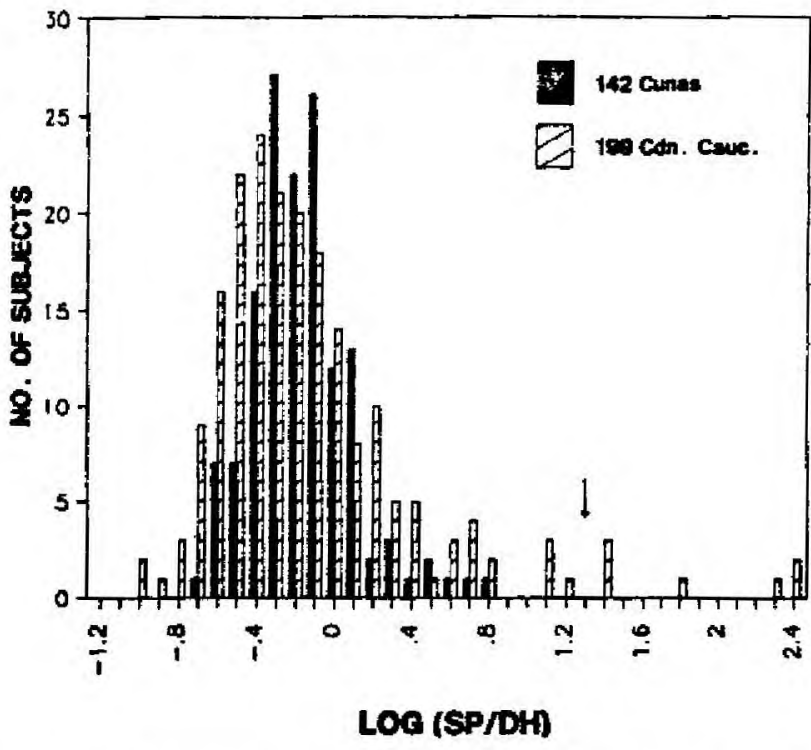

Fig. 1. Frequency histograms of the LMR $(\log S P(D H)$ of 142 unrelated Cuna Amerindians (filled bars) from Panama and 199 unrelated Canadian whites (Can. Cauc.). The Canadian data were pooled from published and unpublished studies by Inaba et al. ${ }^{31}$ and are represented by the hatched bars.

kurtosis has a value of 3 for the normal distribution, whereas flat-topped or platykurtic distributions show values smaller than 3 , and peaked distributions, also known as leptokurtic, have values greater than 3. .1.,19 $^{2}$

Evaluation of the skewness that might characterize the distribution curve of different experimental indexes among various groups and populations provides a refined tool, so far ignored in these studies, to detect the possible existence of subgroups that are not different enough to educe different modes and yet are large enough to introduce deviations from notmality in those cases in which a single mode is found. Of particular significance would be the manifestation of positive skewness in the distribution of metabolic ratios, which cotld suggest the existence of variants with intermediate activities between those corresponding to extensive and those corresponding to poor metabolizers.

\section{RESULTS}

Data for each Cuna subject are presented in Table I: sex, urinary recovery ( 0 - to 12-hour) of sparteine, 2- and 5-dehydrosparteine, total drug, metabolic ratio, and $\log _{10}$ of this ratio (LMR). No significant differences between the means were found (Mann-Whitney U test, $p>0.05$ ) when the amount of drug and metabolites recovered from the various groups were compared with 
Table I. Subject data for urinary elimination of sparteine and its metabolites in 142 Cuna Amerindians of Panama

\begin{tabular}{|c|c|c|c|c|c|c|c|}
\hline $\begin{array}{l}\text { Subject } \\
\text { No. }\end{array}$ & Sex & $\begin{array}{l}S P \\
(\%)\end{array}$ & $\begin{array}{l}D H \\
(\Phi)\end{array}$ & $\begin{array}{c}\text { Sum } \\
(S P+D H)\end{array}$ & $\begin{array}{c}\text { Metabolic ratio } \\
\text { (SP/DH) }\end{array}$ & & $\begin{array}{c}\text { Log metabolic } \\
\text { ratio }\end{array}$ \\
\hline 1 & $\mathbf{M}$ & 5.51 & 14.98 & 20.49 & 0.37 & & -0.43 \\
\hline 2 & $\mathbf{M}$ & 36.34 & 76.84 & 113.18 & 0.47 & & -0.33 \\
\hline 3 & $\mathbf{M}$ & 16.20 & 72.13 & 88.33 & 0.22 & & -0.65 \\
\hline 4 & $\mathbf{F}$ & 24.51 & 49.45 & 73.96 & 0.50 & & -0.30 \\
\hline 7 & $\mathbf{F}$ & 32.52 & 49.44 & 81.96 & 0.66 & . & -0.18 \\
\hline 8 & $\mathbf{F}$ & 18.24 & 74.72 & 92.96 & 0.24 & & -0.61 \\
\hline 9 & $\mathbf{M}$ & 6.48 & 35.17 & 41.65 & 0.18 & & -0.73 \\
\hline 10 & $\mathbf{F}$ & 28.54 & 24.60 & 53.14 & 1.16 & & 0.06 \\
\hline I1 & $\mathbf{M}$ & 23.67 & 36.69 & 60.36 & 0.65 & & -0.19 \\
\hline I2 & $\mathbf{M}$ & 23.36 & 40.69 & 64.05 & 0.57 & & -0.24 \\
\hline 15 & $\mathbf{F}$ & 23.73 & 55.74 & 79.47 & 0.43 & & -0.37 \\
\hline 16 & $\dot{M}$ & 22.65 & 21.22 & 43.87 & 1.07 & & 0.03 \\
\hline 18 & $\mathbf{M}$ & 19.60 & 21.93 & 41.54 & 0.89 & & -0.05 \\
\hline 21 & $\mathbf{M}$ & 27.17 & 25.93 & 53.09 & 1.05 & & 0.02 \\
\hline 22 & $\mathbf{M}$ & 28.89 & 41.01 & 69.91 & 0.70 & & -0.15 \\
\hline 23 & $\mathbf{M}$ & 17.82 & 14.84 & 32.66 & 1.20 & & 0.08 \\
\hline 26 & $\mathbf{M}$ & 19.99 & 32.87 & 52.86 & 0.61 & & $=0.22$ \\
\hline 28 & $\mathbf{M}$ & .12 .24 & 16.51 & 28.75 & 0.74 & & -0.13 \\
\hline 29 & $\mathbf{M}$ & 20.09 & 53.08 & 73.17 & 0.38 & & -0.42 \\
\hline 30 & $\mathbf{M}$ & 14.25 & 27.12 & 41.37 & 0.53 & . & -0.28 \\
\hline 32 & $M$ & 11.17 & 30.63 & 41.80 & 0.36 & & -0.44 \\
\hline 33 & $\mathbf{M}$ & 17.41 & 45.42 & 62.83 & 0.38 & & -0.42 \\
\hline 37 & $\mathbf{F}$ & 5.16 & 12.55 & 17.71 & 0.41 & & -0.39 \\
\hline 38 & $\mathbf{M}$ & 7.50 & 30.75 & 38.25 & 0.24 & & -0.61 \\
\hline 39 & $\mathbf{F}$ & 36.31 & 29.07 & 65.38 & 1.25 & & 0.10 \\
\hline 40 & $\mathbf{F}$ & 22.42 & 31.94 & 54.37 & 0.70 & & -0.15 \\
\hline 41 & $\mathbf{M}$ & 17.60 & 34.63 & 52.23 & 0.51 & & -0.29 \\
\hline 42 & $\mathrm{M}$ & 15.68 & 37.11 & 52.79 & 0.42 & & -0.37 \\
\hline 44 & $\mathbf{M}$ & 28.73 & 48.14 & 76.87 & 0.60 & & -0.22 \\
\hline 48 & $\mathbf{M}$ & 24.35 & 42.38 & 66.72 & 0.57 & - & -0.24 \\
\hline 49 & $\mathbf{F}$ & 4.30 & 13.80 & 18.10 & 0.31 & & -0.51 \\
\hline 56 & $\mathbf{M}$ & 3.20 & 11.40 & 14.60 & 0.28 & & -0.55 \\
\hline 57 & $\mathbf{M}$ & 2.30 & 8.50 & 10.80 & 0.27 & & -0.57 \\
\hline 58 & $\mathbf{M}$ & 6.20 & 22.40 & 28.60 & 0.28 & & -0.56 \\
\hline 39 & $\mathbf{M}$ & 11.72 & 15.97 & 27.68 & 0.73 & & -0.13 \\
\hline 61 & F & 7.41 & 7.78 & 15.19 & 0.95 & & -0.02 \\
\hline 64 & $\mathbf{F}$ & 9.03 & 38.65 & 47.68 & 0.23 & & -0.63 \\
\hline 65 & F & 13.56 & 33.98 & 47.54 & 0.40 & & -0.40 \\
\hline 69 & $F$ & 8.38 & 28.79 & 37.17 & 0.29 & & -0.54 \\
\hline 71 & F & 19.64 & 17.15 & 36.79 & 1.15 & & 0.06 \\
\hline 72 & $\mathbf{F}$ & 17.83 & 29.36 & 47.19 & 0.61 & & -0.22 \\
\hline 75 & $\mathbf{F}$ & 10.92 & 23.29 & 34.20 & 0.47 & & -0.33 \\
\hline 76 & F & 3.35 & 4.37 & 7.72 & 0.77 & & -0.11 \\
\hline 77 & F & 25.98 & 26.87 & 52.84 & 0.97 & & -0.01 \\
\hline 78 & $\mathrm{~F}$ & 29.91 & 28.20 & 58.11 & 1.06 & & 0.03 \\
\hline 79 & $\mathbf{M}$ & 18.22 & 41.34 & 59.56 & 0.44 & & -0.36 \\
\hline 80 & $\mathrm{~F}$ & 11.84 & 18.37 & 30.21 & 0.64 & & -0.19 \\
\hline 81 & $\mathbf{M}$ & 38.60 & 26.62 & 65.23 & 1.45 & & 0.16 \\
\hline 82 & $\mathbf{M}$ & 9.59 & 14.33 & 23.92 & 0.67 & & -0.17 \\
\hline 83 & $\mathbf{M}$ & 3.63 & 7.25 & 10.89 & 0.50 & & -0.30 \\
\hline 85 & $\mathrm{~F}$ & 13.44 & 35.73 & 49.17 & 0.38 & & -0.42 \\
\hline 86 & $F$ & 4.68 & 14.81 & 19.49 & 0.32 & & -0.50 \\
\hline 88 & $\mathrm{~F}$ & 16.71 & 28.01 & 44.72 & 0.60 & & -0.22 \\
\hline 89 & $\mathrm{~F}$ & 50.23 & 13.00 & 63.23 & 3.86 & & 0.59 \\
\hline 91 & F & 19.67 & 7.39 & 27.06 & 2.66 & & 0.43 \\
\hline 92 & $\mathrm{~F}$ & 13.53 & 26.62 & 40.15 & 0.51 & & -0.29 \\
\hline
\end{tabular}

SP, sparteine: DH. dehydrosparteinc.

Subject Nos. 1-82 and 168-178 were from Panama Cig; subject Nos. 83-167 were from: Rio Azucar: subrect Nos. 179-203 were from Kuna-Nega 
Table I, -Cont'd

\begin{tabular}{|c|c|c|c|c|c|c|c|c|c|}
\hline $\begin{array}{c}\text { Subject } \\
\text { no. }\end{array}$ & Sex & $\underset{(\$)}{S P}$ & $\begin{array}{l}D H \\
(\%)\end{array}$ & $\begin{array}{c}S u m \\
(S P+D H)\end{array}$ & & $\begin{array}{c}\text { Metabolic ratic } \\
(S P / D H)\end{array}$ & & & $\begin{array}{c}\text { Log metabolic } \\
\text { ratio }\end{array}$ \\
\hline 93 & $\mathbf{F}$ & 6.00 & 12.51 & 18.52 & & 0.48 & & & -0.32 \\
\hline 95 & $F$ & 9.29 & 17.57 & 26.85 & & 0.53 & & & -0.28 \\
\hline 96. & $\mathbf{F}$ & 6.43 & 30.16 & 36.60 & & $0.2 !$ & & & -0.67 \\
\hline 97 & $\mathbf{F}$ & 12.48 & 31.82 & 44.31 & & 0.39 & & & -0.41 \\
\hline 99 & $\mathbf{F}$ & 13.47 & 19.75 & 33.22 & . & 0.68 & , & & -0.17 \\
\hline 100 & $\mathbf{M}$ & 12.86 & 15.66 & 28.52 & & 0.82 & . & & -0.09 \\
\hline 101 & $\mathbf{F}$ & 11.92 & 22.97 & 34.90 & & 0.52 & & . & -0.28 \\
\hline 102 & $\mathbf{F}$ & 7.80 & 23.80 & 31.60 & & 0.33 & & & -0.48 \\
\hline 104 & $\mathbf{F}$ & 10.50 & 14.04 & 24.54 & & 0.75 & & & -0.13 \\
\hline 105 & $\mathbf{F}$ & 6.43 & 10.05 & 16.48 & & 0.64 & & & -0.19 \\
\hline 107 & $\mathbf{F}$ & 29.86 & 32.32 & 62.18 & - & 0.92 & & & -0.03 \\
\hline 108 & $F$ & 20.56 & 30.39 & 50.96 & & 0.68 & & & -0.17 \\
\hline 110 & $\mathbf{F}$ & 17.31 & 32.55 & 49.86 & & 0.53 & & & -0.27 \\
\hline 111 & $\mathbf{F}$ & 23.26 & 34.19 & 57.45 & & 0.68 & & . & -0.17 \\
\hline 112 & F & 13.90 & 32.28 & 46.18 & & 0.43 & & . & -0.37 \\
\hline ( 113 & F & 35.40 & 41.39 & 76.78 & & 0.86 & & & -0.07 \\
\hline 117 & $\mathbf{M}$ & 29.82 & 21.80 & 51.61 & & 1.37 & & & 0.14 \\
\hline 118 & $\mathbf{M}$ & 29.40 & 27.02 & 56.41 & & 1.09 & & & 0.04 \\
\hline 119 & $\mathbf{M}$ & 15.25 & 44.14 & 59.40 & & 0.35 & & & -0.46 \\
\hline 120 & $\mathbf{M}$ & 21.50 & 26.70 & 48.21 & & 0.81 & & & -0.09 \\
\hline 121 & $\mathbf{F}$ & 10.66 & 47.60 & 58.26 & & 0.22 & & & -0.65 \\
\hline 123 & $\mathbf{M}$ & 16.56 & 22.33 & 38.89 & & 0.74 & & & -0.13 \\
\hline . $\quad 124$ & $\mathbf{M}$ & 21.40 & 20.83 & 42.22 & $:$ & 1.03 & & & 0.01 \\
\hline 125 & $\mathbf{F}$ & 6.48 & 9.11 & 15.58 & & 0.71 & & & -0.15 \\
\hline 126 & $\cdot \vec{F}$ & 26.83 & 4.71 & 31.54 & & 5.70 & & & 0.76 \\
\hline 128 & $\mathbf{F}$ & 20.09 & 48.64 & 68.73 & & 0.41 & & & -0.38 \\
\hline 129 & $\mathbf{F}$ & 19.48 & 39.51 & 58.99 & & 0.49 & & & -0.31 \\
\hline 130 & F & 28.69 & 40.13 & 68.82 & & 0.71 & & - & -0.15 \\
\hline 132 & F & 22.58 & 20.37 & 42.95 & & 1.11 & . & & 0.04 \\
\hline 134 & $\mathbf{M}$ & 13.07 & 3.02 & 16.09 & 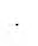 & 4.32 & & & 0.64 \\
\hline 136 & $\mathbf{F}$ & 13.38 & 36.47 & 49.85 & & 0.37 & & & -0.44 \\
\hline 137 & $\mathbf{F}$ & 32.95 & 34.40 & 67.35 & & 0.96 & & & -0.02 \\
\hline 141 & $\mathbf{M}$ & 9.95 & 11.36 & 21.31 & & 0.88 & & & -0.06 \\
\hline 142 & $M$ & 18.44 & 59.54 & 77.98 & & 0.31 & & & $-0.5 t$ \\
\hline 143 & $\mathbf{M}$ & 19.09 & 46.05 & 65.14 & & 0.41 & & & -0.38 \\
\hline 144 & $\mathbf{M}$ & 9.91 & 8.39 & 18.30 & & 1.18 & & & 0.07 \\
\hline 145 & $\mathbf{M}$ & 4.13 & 9.87 & 14.01 & & 0.42 & & & -0.38 \\
\hline 146 & $\mathbf{M}$ & 10.88 & 5.01 & 15.89 & & 2.17 & & & 0.34 \\
\hline 147 & $\mathbf{F}$ & 15.62 & 40.21 & 55.83 & & 0.39 & & & -0.41 \\
\hline 148 & $\mathbf{M}$ & 23.12 & 25.77 & 48.89 & & 0.90 & & & -0.05 \\
\hline 150 & $\mathbf{M}$ & 12.75 & 7.68 & 20.42 & & 1.66 & & & 0.22 \\
\hline 151 & $\mathbf{M}$ & 8.29 & 17.73 & 26.01 & & 0.47 & & & -0.33 \\
\hline 152 & $F$ & 7.36 & 19.60 & 26.95 & & 0.38 & & & -0.43 \\
\hline 153 & $\mathbf{M}$ & 6.84 & 14.84 & 21.68 & & 0.46 & & & -0.34 \\
\hline 154 & $\mathbf{M}$ & 19.80 & 27.40 & 47.20 & & 0.72 & & & -0.14 \\
\hline 155 & $\mathbf{M}$ & 20.51 & 36.20 & 56.71 & & 0.57 & & & -0.25 \\
\hline 156 & $\mathbf{M}$ & 19.57 & 33.98 & 53.55 & & 0.58 & & & -0.24 \\
\hline 157 & $\mathbf{M}$ & 5.74 & 15.99 & 21.73 & & 0.36 & & & -0.45 \\
\hline 158 & $\mathbf{M}$ & 8.68 & 12.75 & 21.43 & & 0.68 & & & -0.17 \\
\hline 159 & $\mathbf{M}$ & 27.01 & 14.62 & 41.64 & & 1.85 & & & 0.27 \\
\hline 163 & $\mathbf{M}$ & 30.97 & 29.09 & 60.06 & & 1.06 & & & 0.03 \\
\hline 164 & $\mathbf{M}$ & 33.48 & 18.90 & 52.37 & & 1.77 & & & 0.25 \\
\hline 165 & $\mathbf{M}$ & 5.12 & 10.61 & 15.72 & & 0.48 & & & -0.32 \\
\hline 166 & $\mathbf{M}$ & 22.82 & 39.35 & 62.18 & & 0.58 & & & -0.24 \\
\hline 167 & $\mathbf{M}$ & 13.44 & 19.13 & 32.57 & & 0.70 & & & -0.15 \\
\hline 168 & $\mathrm{M}$ & 9.62 & 19.09 & 28.71 & & 0.50 & & & -0.30 \\
\hline 169 & $\mathrm{~F}$ & 31.11 & 32.23 & 63.33 & & 0.97 & & & -0.02 \\
\hline
\end{tabular}


Table I. -Cont'd

\begin{tabular}{|c|c|c|c|c|c|c|}
\hline $\begin{array}{l}\text { Subject } \\
\text { no. }\end{array}$ & Sex & $\begin{array}{l}S P \\
\left(\Phi_{0}\right)\end{array}$ & $\begin{array}{l}D H \\
(\%)\end{array}$ & $\begin{array}{c}\text { Sum } \\
(S P+D H)\end{array}$ & $\begin{array}{c}\text { Metabolic ratio } \\
(\text { SP } / D H)\end{array}$ & $\begin{array}{l}\text { Log metabolic } \\
\text { ratio }\end{array}$ \\
\hline 170 & $\mathbf{F}$ & 2.39 & 6.56 & 8.95 & 0.36 & -0.44 \\
\hline 171 & $\mathbf{M}$ & 25.00 & 40.83 & 65.83 & 0.61 & -0.21 \\
\hline 172 & $\mathbf{M}$ & 9.02 & 21.20 & 30.22 & 0.43 & -0.37 \\
\hline 173 & $\mathbf{F}$ & 20.17 & 44.84 & 65.01 & 0.45 & -0.35 \\
\hline 174 & $\mathbf{M}$ & 7.40 & 13.36 & 20.76 & 0.55 & -0.26 \\
\hline 175 & $\mathbf{F}$ & 9.88 & 17.12 & 27.00 & 0.58 & -0.24 \\
\hline 176 & $\mathbf{M}$ & 6.95 & 13.71 & 20.66 & 0.51 & -0.29 \\
\hline 177 & $\mathbf{M}$ & 15.78 & 22.92 & 38.70 & 0.69 & -0.16 \\
\hline 178 & $\mathbf{M}$ & 30.65 & 32.81 & 63.46 & 0.93 & -0.03 \\
\hline 179 & $\mathbf{F}$ & 26.33 & 33.27 & 59.60 & 0.79 & -0.10 \\
\hline 180 & $\mathbf{M}$ & 24.84 & 35.30 & 60.14 & 0.70 & -0.15 \\
\hline 181 & $\mathbf{M}$ & 16.89 & 21.96 & 38.85 & 0.77 & -0.11 \\
\hline 183 & $\mathbf{F}$ & 15.89 & 39.84 & 55.73 & 0.40 & -0.40 \\
\hline 184 & $\mathbf{M}$ & 13.25 & 29.79 & 43.03 & 0.44 & -0.35 \\
\hline 185 & $\mathbf{F}$ & 7.16 & 13.08 & 20.24 & 0.55 & -0.26 \\
\hline-86 & $\mathbf{M}$ & 15.03 & 33.51 & 48.55 & 0.45 & -0.35 \\
\hline .7 & $\mathbf{M}$ & 9.66 & 13.95 & 23.61 & 0.69 & $-0: 16$ \\
\hline 189 & $\mathbf{F}$ & 21.09 & 29.42 & 50.50 & 0.72 & -0.14 \\
\hline 190 & $\mathbf{M}$ & 8.64 & 19.15 & 27.79 & 0.45 & -0.35 \\
\hline 191 & $\mathbf{F}$ & 22.97 & 7.69 & 30.66 & 2.99 & 0.48 \\
\hline 193 & $\mathbf{M}$ & 7.37 & 29.39 & 36.76 & 0.25 & -0.60 \\
\hline 194 & $\mathbf{M}$ & 6.00 & 13.93 & 19.93 & 0.43 & -0.37 \\
\hline 195 & $\mathbf{F}$ & 4.77 & 7.90 & 12.67 & 0.60 & -0.22 \\
\hline 198 & $\mathbf{M}$ & 27.20 & 25.94 & 53.14 & 1.05 & 0.02 \\
\hline 199 & $\mathbf{F}$ & 5.75 & 14.84 & 20.59 & 0.39 & -0.41 \\
\hline 200 & $\mathbf{M}$ & 7.22 & 14.30 & 21.52 & 0.51 & . -0.30 \\
\hline 201 & $\mathbf{F}$ & 4.75 & 10.22 & 14.97 & 0.46 & -0.33 \\
\hline 202 & $\mathbf{M}$ & 17.68 & 38.80 & 56.48 & 0.46 & -0.34 \\
\hline 203 & $\mathbf{F}$ & 26.04 & 44.01 & 70.05 & 0.59 & -0.23 \\
\hline
\end{tabular}

those of Río Azícar, nor were there differences when the metabolic ratios were compared. Their descriptive statistics are presented in Table II and the results are grouped according to the place of collection as well.

Because the data were independent of the place, poc data were used for the subsequent calculations. In those 142 subjects, total urinary recoveries (0- to 12 hour) of sparteine, 2- and 5-dehydrosparteine, and the total percentage of drug excreted were $16.6 \% \pm 9.3 \%$ (SD), $26.6 \% \pm 14.4 \%$, and $43.3 \% \pm 20.3 \%$, respectively. The values of the metabolic ratio ranged widely, with a mean of $0.76 \pm 0.72(\mathrm{LMR}=-0.21 \pm$ $0.26)$ and a median value of $0.58(\mathrm{LMR}=-0.24)$; limits were 0.18 and $5.70(L M R=-0.73$ and 0.76$)$ with a range of $5.52(\mathrm{LMR}=1.49)$.

The frequency distribution histogram of LMR is shown in Fig. 1 and its probit plot in Fig. 2. Absence of an antimode in Fig. 1, as well as the general linearity in the probit plot, with the exception of an inflection point at 6.3 probit $\mathrm{U}$, indicates the absence of a group in the Cuna population that could be associated with the presence of deficient metabolizers. Furthermore, none of the 28 subjects who were excluded because of the consanguinity criterion had a metabolic ratio higher than the mean value 0.76 . Among this total of 170 observations, there were no deficient metabolizers of sparteine.

In Fig. 1 the LMR of whites living in Toronto, Canada, were plotted alongside; in this population, using an antimode of 1.3 , seven subjects ( $3.5 \%$ ) are classified as deficient metabolizers. The Cuna and white extensive metabolizers exhibited similar distribution histograms. In Fig. 2 slight deviations from the straight line in the upper range of probit values, in both the Cuna and Ghanaian subjects, are also observed. However, these departures from normality are not as marked as those observed in multimodal distributions and are likely associated with certain departures of normality commented on below.

The results of the $\chi^{2}$ goodness-of-fit test rejected the hypothesis, at acceptable levels of significance $(\alpha=$ 0.05 ), that the LMR of sparteine follows a normal dis- 
Table II. Summary of the urine recovery of sparteine and 2- and 5-dehydrosparteines in 142 unrelated Cuna Amerindians from three places

\begin{tabular}{|c|c|c|c|c|c|}
\hline $\begin{array}{l}\text { Place of } \\
\text { collection }\end{array}$ & Statistics & Sparteine & Dehydrosparteine & $\begin{array}{c}\text { Total drug } \\
(S P+D H)\end{array}$ & $\begin{array}{c}L M R \\
(S P / D H)\end{array}$ \\
\hline $\begin{array}{l}\text { Panama city } \\
(n=60) \\
\text { Rio Azucar } \\
(n=62) \\
\text { Chivo-Chivo } \\
(n=20) \\
\text { Total population } \\
(n=142)\end{array}$ & $\begin{array}{l}\text { Mean } \pm \text { SD } \\
\text { Median } \\
\text { Mean } \pm \text { SD } \\
\text { Median } \\
\text { Mean } \pm \text { SD } \\
\text { Median } \\
\text { Mean } \pm \text { SD } \\
\text { Median } \\
\text { Skewness } \dagger \\
\text { Kurtosist }\end{array}$ & $\begin{array}{c}17.1 \pm 9.6 \\
17.5 \\
16.8 \pm 9.3 \\
17.5 \\
14.4 \pm 8.0 \\
14.1 \\
16.6 \pm 9.3 \\
15.7 \\
-0.55 \ddagger \\
2.66 \$\end{array}$ & $\begin{array}{c}30.1 \pm 16.1 \\
28.5 \\
24.3 \pm 12.8 \\
22.7 \\
23.8 \pm 11.5 \\
24.0 \\
26.7 \pm 14.4 \\
26.3 \\
-0.67 \ddagger \\
3.238\end{array}$ & $\begin{array}{c}47.2 \pm 22.8^{*} \\
47.4 \\
41.1 \pm 18.1 \\
42.6 \\
38.2 \pm 17.6^{*} \\
37.8 \\
43.3 \pm 20.3 \\
43.0 \\
-0.63 \ddagger \\
2.69 \$\end{array}$ & $\begin{array}{c}-0.26 \pm 0.21^{*} \\
-0.25 \\
-0.16 \pm 0.29 \\
-0.18 \\
-0.23 \pm 0.22^{*} \\
-0.28 \\
-0.21 \pm 0.26 \\
0.24 \\
1.00 \neq \\
4.95\end{array}$ \\
\hline
\end{tabular}

SP, spartine; DH, dehytrosparteine.

No significan differences $(p>0.05)$ conpared with Rio Aarcur by Man-Whitney U vest.

sog values (e.t. los [SPD were used.

tNegative skewness ( $<1 \%$, lower tail)

No significant turtosis (>5\%).

Prositive kurtosis $(<1 \%$, peated distribution).

tribution, thus confirming the observed nature of the corresponding probit plot. This departure from normality is described in Table III in terms of skewness and kurtosis for the Cuna and other populations discussed elsewhere.

In addition to the descriptive statistics of the Cuna data, we have included in Table III, for comparison purposes, similar data for Ghanaian blacks and Canadian whites. Because we wished to examine in closer detail the nonwhite populations, which lack deficient metabolizers, and compare them with the group of white extensive metabolizers, we bave presented their descriptive statistics in separate columns, one for the mole white population and another for the group of ensive metabolizers.

Inspection of Table III reveals that the distribution curves for all three populations showed positive skewness, as well as leptokurtic character, with a maximum value in Canadian whites, as expected by the presence of two groups of metabolizers. Similar values are shown for Cuna Amerindians and white extensive metabolizers and a minimum value for Ghanaian blacks. The departures from normality found in these black subjects had already been .reported by Eichelbaum and Woolhouse.

\section{DISCUSSION}

Absence of deficient metabolizers in the Cuna sample population studied. Because the present study was the first to evaluate oxidative metabolism in any Amerindian group, particular attention was paid to the ethnic homogeneity and general phylogenic relations of the population studied. Results of genetic studies carried out simuitaneously with this one and to be published elsewhere (Neel JV, personal communication) confirm our original expectations arising from earlier observations ${ }^{15.16}$. the Cuna population of Rio Azucar is characterized by a low racial admixture (i.e., <1\%). It was also estimated that the Cuna's genetic divergence with neighboring Amerindian groups occurred at least 3000 to 5000 years ago.

For the above reason we have used the community of Rio Azúcar as the reference population in comparing data obtained in the other two locations: Kuna Nega and Panama City. Because the results of samples collected in other communities were not significantly different from those of the reference population, we combined the data originating in these locations.

The LMR indicates that the Cuma sample population studied, unlike whites, ${ }^{4}$ is not characterized by the presence of deficient metabolizers. This can be appreciated by the absence of an antimode in Fig. 1, as well as by the nature of the respective curve in its probit plot as shown in Fig. 2. In addition, the highest value found for the metabolic ratio was 5.70 (LMR $=0.76$ ), which is about three and a half times smaller than the antimode value in whites to whom the value of $20(L M R=1.3)$ has been assigned."

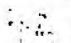

The absence of deficient metabolizers among those 28 subjects who were excluded because of their close consanguinity relations further supports our belief, based on a total of 170 subjects studied, that the Cuna subjects in our sample population are not characterized by a group of poor metabolizers. 


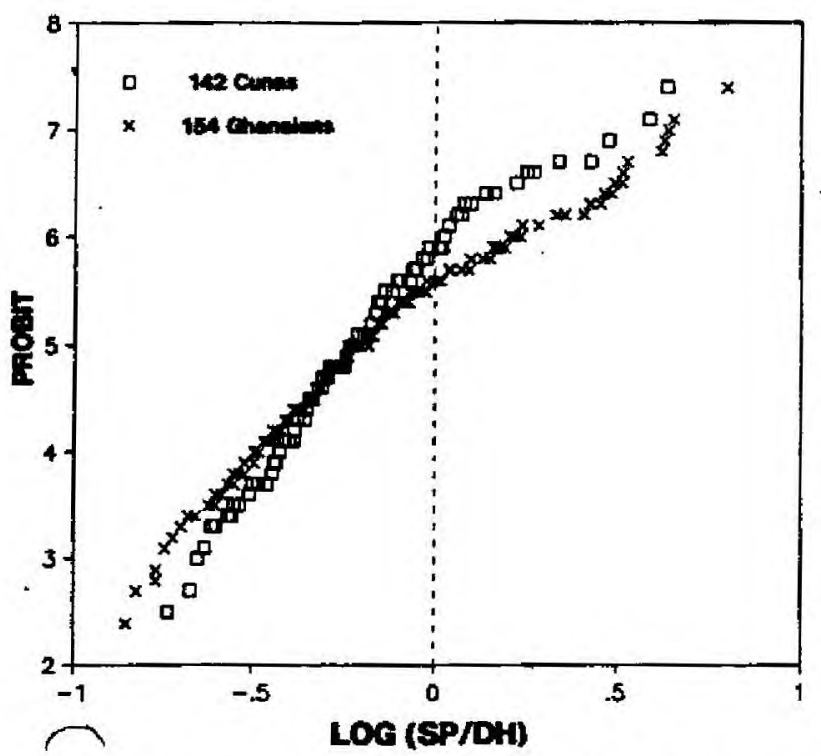

Fig. 2. Probit plots of the LMR $(\log S P / D H)$ from 142 Cuna Amerindians and 154 Ghanaians reported by Eichelbaum and Woolhouse..$^{5}$ No significant differences $(p>0.05)$ were found by the Mann-Whitney $U$ test.

Absence of deficient metabolizers in the Cuna sample and its implication for the existence of polymorphism in this population. The existence of an inflection point in the probit plot shown in Fig. 2 at 6.3 probit $U$ $(92.5 \%$ or $7.5 \%$ ) should be taken as indicative of the existence of at least two subgroups congregating within the same mode of the distribution curve. The largest subgroup could correspond to $92.5 \%$ of the total subjects and the smallest to $7.5 \%$. The dividing line is estimated to be at LMR $=0.125$. Indeed, the two subgroups could correspond to both homozygous dominan (AA) and heterozygous (Aa) subjects of the wellkı a white phenotypes.

Having concluded that the existence of the inflection point does not allow the exclusion of heterozygous ( $\mathrm{Aa}$ ) subjects in the Cuna population sample studied, the use of this point to determine the number of heterozygous subjects must be evaluated. To accomplish this, instead of using the Cuna data that present limitations for this purpose, because no homozygous-recessive subjects have been observed in our sample, one can use the Canadian white data shown in Fig. I, a population in which they are known to exist. From the inflection point the number of heterozygous subjects can be estimated to be $5.4 \%$ of the total population, which in fact is lower than the $7.5 \%$ estimated for the Cunas.

These results merit further analysis on the basis of comparisons between these two ethnic groups be- cause they are contradictory with the existence of homozygous-recessive subjects (aa) or poor metabolizers found in the Canadians and the absence of poor metabolizers in the sample studied. In fact the number of heterozygotes should be higher in Canadians than in the Cunas population at large. This point is discussed further in the following section.

According to the Hardy-Weinberg law, if the frequency of poor metabolizers $=7 / 199$ in the Canadian white $(q=0.19)$, the number of the estimated heterozygous subjects would be $31 \%$. There is then a very serious discrepancy between the values calculated by the Hardy-Weinberg law and those using the inflection point, $31 \%$ vs. $5.4 \%$, as indicated above. This disagreement weakens the validity of this approach when used to estimate the number of heterozygous subjects. This could be the result of at least one of the assumptions inherent in this approach (i.e., an invariable, precise correspondence between genotypes of the white type, in this case homozygous dominant (AA) and heterozygous (Aa), and their phenotypic expression). However, this assumption can be questioned as inferred from published works, for instance, Steiner et al. ${ }^{20}$ (Eichelbaum, personal communication).

The overall genetic structure of Amerindians includes many more monomorphormic loci and rare variants than in white populations, probably as a result of a more pronounced genetic drift and endogamy. ${ }^{3.14 .21-24}$ It is therefore conceivable that some of the subjects in the smaller subgroup present in the single mode might carry a mutant allele, as has been suggested for Ghanaians. ${ }^{25}$ The corresponding cytochrome $\mathrm{P}-450$ isozyme might have slightly altered catalytic properties. Therefore this tentative proposal entails the existence of three different alleles: the classic white ones, $\mathrm{A}$ and $\mathrm{a}$, and $\mathrm{a}$ third mutant allele. The inflection point might divide the subjects carrying this mutant allele from the white homozygous-dominant and heterozygote populations.

In conclusion, our presently available data do not allow us to reacb conclusions regarding polymorphism or its absence in the Cuna population at large from the results obtained in the Cuna population sample studied, for two reasons: (1) those associated with the assumptions inherent in the method represented by the use of the inflection point and (2) conflicting criteria that are used to determine the existence of polymorphism, among other things. ${ }^{36-29}$ We intend to address these crucial points in a future publication.

The Cuna and certain other ethnic groups: Canadian whites and black Ghanaians. It is interesting to contrast the results obtained in the Cuna to those of Canadian whites. ${ }^{36.34}$ as shown in the two histograms 
Table III. Sparteine metabolic ratios in Cuna Amerindians, black Ghanaians, and Canadian whites

\begin{tabular}{lcccc}
\hline $\begin{array}{c}\text { Metaiolic ratio log } \\
(S P / D H)\end{array}$ & $\begin{array}{c}\text { Cuna } \\
\text { Amerindians } \\
(n=142)\end{array}$ & $\begin{array}{c}\text { Ghanaian } \\
\text { blacks } \\
(n=I S 4)^{*}\end{array}$ & $\begin{array}{c}\text { Whites } \\
(n=192 ; E M) \dagger\end{array}$ & $\begin{array}{c}\text { Whites } \\
(n=199 ; E M+P M)^{\dagger}\end{array}$ \\
\hline Mean I SD & $-0.21 \pm 0.26$ & $-0.18 \pm 0.36$ & $-0.24 \pm 0.40$ & $-0.16 \pm 0.56$ \\
Mectian & -0.24 & -0.24 & -0.31 & -0.28 \\
Minimum/maximum & $-0.73 / 0.76$ & $-0.85 / 1.10$ & $-1.06 / 1.15$ & $-1.06 / 2.58$ \\
Skewness & $1.00 \ddagger$ & $0.79 \ddagger$ & $1.01 \ddagger$ & $2.15 \ddagger$ \\
Kertosis & $4.95 \S$ & $3.63 \|$ & $4.23 \S$ & $9.41 \$$ \\
\hline
\end{tabular}

SP, spenteine; DH, debydrosparteine; EM, extensive metabolizer, PM, poon motabolizer.

"Den from Eichelbanm and Woolhouse."

tCanadian dats (see Fig. 1).

tPoqitive skewness ( $<i \%$, upper (nil).

SPasitive kurtosis ( $<1 \%$, penked distribution).

Wo significant kurtosis (>5\%).

in Fig. 1. As a whole, the two populations are distinThable by the absence in the Cuna of the group 1 v r resented by the deficient metabolizers found in this white population ( $3.5 \%$ ). However, equally remarkable are the similarities observed for the two groups of extensive metabolizers; the distributions, although not quantitatively identical (mean/median, Cuna $=$ 0.875 ; white $=0.774$ ), are suggestively similar (skewness values: Cunas $=1.00$; Canadian whites $=1.01$ ) These differences and similarities are also shown in Table III.

To the extent that these two populations are similar and to the degree that we have not seen deficient metabolizers in the Cuna sample studied, the probable number of heterozygotes (Aa) in this sample should decrease and, thus, their contribution to one of the observed subgroups present in the single mode should also diminish. If we assume that in the Cuna population the frequency of poor metabolizers is similar to that found in Canadian whites (3.5\%), the probability of ing all subjects extensive metabolizers in the 170 L Laas examined would be 0.0023 or, vice versa, the probability of not finding a poor metabolizer in 170 subjects would be 0.0023 . If we use the more commonly accepted figure of $5.4 \%$ of poor metabolizers in whites, the probability would be less than 0.0016 . Although this is not a convincing argument per se and assumes certain similarities between the Cuna population and the largest mode of the Canadian whites, it reinforces our suggestion for the existence of a nonwhite isozyme, as indicated above.

The absence of deficient metabolizers is a trait that the Cuna share with the Ghanaians-studied by Eichelbaum and Woolhouse. ${ }^{5}$ To compare these two populations, we have presented in Fig. 2 the results of their study together with ours. The lines intersect at about a probit value of 5 , indicating the same median and possibly the same mean values. After we calculated the pertinent parameters from the published data, ${ }^{5}$ as shown in Table III, we could confirm these observations by the Mann-Whitney $U$ test.

Moreover, the data of the Cunas showed a steeper slope, indicating an even namower distribution or less variability than the Ghanaians. This is consistent with the predominant genetic control of sparteine biotransformation ${ }^{4}$ and the genetic homogeneity of the Cunas noted above, a result that is apparent from its very low racial admixture with respect to both nonAmerindians and Amerindian groups. It is logical to expect that genetically homogeneous populations should show less dispersion of phenotypic characteristics than others that are less so. In fact, these results are consistent with the relative homogeneity of blood groups found in certain African groups and Amerindians. ${ }^{24}$

The limiting values of sparteine metabolic ratio for these two groups also compare favorably: 0.18 to 5.70 for the Cunas vs. 0.14 to 12.5 for the Ghanaians. Nevertheless, the skewness value for the Ghanaians is smaller $(0.79)$ than are those for the Cunas $(1.00)$ and the white extensive metabolizers (1.01), as can be seen in Table IIl. As discussed above on the basis of the probit plots, there is a greater dispersion of values in the Ghanaians compared with the Cunas; the values of the Ghanaians are more symmetrically distributed about the man, as indicated by the skewness.

Conclusions. The results of the present study, appreciated in the light of all those carried out in nonwhite populations: Ghanaian blacks" and Japanese" (Inaba T, Kalow $W$, personal communication), indicate that the frequency of deficient metabolizers of spaneine is not as widespread as would have been expected from the 
results found in whites. It is therefore logical to conclude that the frequency of deficient metabolizers of a particular oxidative pathway in one population does not necessarily translate itself into others, or even that the presence of polymorphism in one ethnic group does not guarantee its existence in others.

In addition, the possible existence of nonwhite-type isozyme variants should be kept in mind in the investigation of ethnic groups in general and the interpretation of deviations from normality in unimodally distributed curves in particular.

We thank Drs. G. Tucker and M. Eichelbaum for helpful and generous suggestions. We also appreciate the constructive criticism offered by one of the anonymous reviewers of this article. In addition, we acknowledge the support of the following persons during the field work phase of this study: $\mathbf{M r}$. Y Duke, Drs. Francisco Rivera, Margriet Blaauw, and V. ..tam Brenes, Messrs. Roberto Preciado, Lino Smith, Alberto Martínez, and Francisco Andreve, Ms. Reyna Gareia, and Mrs. Lesbia Anderson. We also thank Messrs. Jesís Escobar and Camilo Jorge, Ms. Nilka Guemero de Solís, and Rosa Caballero for their skillful technical assistance. We express special thanks to the Cuna communities visited for the hospitality and cooperation shown, which made this work possible.

\section{References}

1. Eichelbaum M. Defective oxidation of drugs: pharmacokinetic and therapeutic implications. Clin Pharmacokinet 1982;7:1-22.

2. Sjöqvist F, Bertilsson L. Slow hydroxylation of tricyclic antidepressants - relationship to polymorphic dng oxidation. In: Kalow W, Goedde HW, Agarwal DP, cds. Ethric differences in reactions to drugs and xenobiotics. New York: Alan R Liss, 1986:169-88.

3. Lennard MS, Tucker GT, Silas JH, Woods HF. Debrisoquine polymorphism and the metabolism of metoprolol, timolol, propranolol and atenolol. Xenobiotica 1986; 16:435-47.

4. Eichelbaum M, Reitz K-P, Schmidt EK. Zekorn C. The genetic polymorphism of sparteine metabolism. Xenobiotica 1986;16:465-81.

5. Eichelbaum $\mathbf{M}$, Woolhouse $\mathbf{N M}$. Interethnic difference in sparteine oxidation among Ghanaians and Germans. Eur J Clin Pharmacol 1985:28:79-83.

6. Ishizaki T. Eichelbaum M, Horai Y. Hashimoto $K$. Chiba K. Dengler HJ. Evidence for polymorphic oxidation of sparteine in Japanese subjects. Br J Clin Pharmacol 1987:23:482-5.

7. Rodríguez N. Soubie E. La población indigena actua] en América Latina. Nueva Antropol 1978:3:49.

8. Mayer E. Masferrer E. La población indigena de América en 1978. Am Inüigena 1978:39:217-37.

9. Deutsche Press Agentür. El 8.7 por ciento de la población de 15 paises latinoamericanos es de origen indfgena. , Prensa (Panama) 1986;24:5b.

10. Arias TD, Jorge LF, Inaba T. No evidence for the presence of poor metabolizers of sparteine in an Amerindian group: the Cunas of Panamá. Br J Clin Pharmacol 1986;21:547-8.

11. Arias TD, Jorge LF, Lee D, et al. La biotransformación de la esparteína en Amerindios Cunas de Panamá. Rev Med Panama 1986;11:199-209.

12. Official Census, with projections, Republic of Panama, 1980.

13. Barrantes R, Smouse PE, Neel JV, Mohrenweiser HW, Gershowiz H. Migration and genetic infrastructure of the Central American Guaymi and their affinities with other tribal groups. Am J Phys Anthropol 1982;58: $201-14$.

14. Spieiman RS, Migliazza EC, Neel JV, Gershowithz H, de Arauz RT. The evolutionary relationships of two populations: a study of the Guaymi and the Yanomama. Curr Antropol 1979;20:377-88.

15. Matson A, Swanson J. Distribution of hereditary blood antigens among Indians in middle America. VIII. Panama. Am J Phys Anthropol 1965;23:413-26.

16. Matson GA, Sutton HE, Swanson 3, Robinson AR. Distribution of haptoglobin, transferrin, and hemoglobin types among Indians of middle America: in British Honduras, Costa Rica and Panama. Am J Phys Anthropol 1965;23:123-30.

17. Inaba T, Vinks A, Otton SV. A simple borohydride/GC method for measuring sparteine metabolites in man. $\mathrm{Br}$ J Clin Pharmacol 1986;21:473-80.

18. Snedecor GW, Cochran WG. Statistical methods. 6th ed. Ames: lowa State University Press, 1976:84-9.

19. Wright S. Genetic and biometric foundations. In: Evo- lution and the genetics of population. Chicago: The University of Chicago Press, 1968:211-20.

20. Stcinke E, Iselius L, Alvan G, Lindsten J, Sjöqvist FA. A family study of genetic and envinonmental factors determining polymorphic bydroxylation of debrisoquin in man. Cun Pharmacol. Ther 1985;38:394-401.

21. Neel JV. Rare variants, private polymorphisms, and locus heterozygosity in Amerindian populations. Am J Hum Genet 1978:30:465-90.

22. Neel JV, Salzano FM. A prospectus for genetic studies of the American Indian. Cold Spring Harbor Symp Quant Biol 1964:29:95-8.

23. Neel JV, Layrisse M, Salzano F. Man in the tropics: the Yanomama Indians. In: Harrison GA. ed. Population structure and human variation. Cambridge: Cambridge University Press, 1977:109-42.

24. Mourant AE. Kopec AC, Domanie DomaniewskaSohczak K. The distribution of the human blood groups and other polymorphism. 2nd cd. London: Oxford University Press, 1976:353-71.

25. Woolhouse NM. The debrisoquin isparteine oxidation polymorphism: evidence of genetic heterogeneity among Ghanaians. In: Kalow W. Goedde HW, eds. Ethnic dif- 
ferences in reaction to dings and other xenobiotics. New York: Alan R Liss, 1985:189-203.

26. Vogel F, Motulsky AG. Human genetics: problems and approaches. 2nd ed. New York: Springer-Verlag, 1986: 435.

27. Harris H. Principles of human biochemical genetics. 3rd ed. New York: Elsevier Science Publishing, 1980.

28. Cavalli-Sforza LL, Bodmer WF. Genetics of human populations. San Francisco: Freeman, Cooper \& Co, 1981: $118-9$.
29. Nei M. Evolutionary genetics. New York: Columbia Uni- , versity Press, 1987:176-7.

30. Inaba T, Vinks A, Otton SV, Kalow W. Comparative pharmacogenetics of sparteine and debrisoquin. CLIN Pharmacol. Ther 1983;33:394-9.

31. Inaba $T$, Jurima $M$, Nakano $M$, Kalow $\mathbf{W}$. Mephenytoin and sparteine pharmacogenetics in Canadian Caucasians. Clun Pharmacol Ther 1984;36:670-6. 